\title{
Quality and safety issues related to traditional animal medicine: role of taurine
}

\author{
Kyoko Takahashi ${ }^{1,2}$, Yuko Azuma ${ }^{2}$, Kayoko Shimada ${ }^{2}$, Tadashi Saito ${ }^{3}$, Masaya Kawase ${ }^{4}$, Stephen W Schaffer ${ }^{5}$ \\ From $17^{\text {th }}$ International Meeting of Taurine \\ Fort Lauderdale, FL, USA. 14-19 December 2009
}

\begin{abstract}
Background: Calculus Bovis (:C.Bovis) is one of the most precious and commonly-used medicinal materials in Japan and China. As the natural occurrence is very rare, a source of supply for $C$. Bovis is far behind the actual need and great efforts have been taken for some substitutes of natural C. Bovis. Unfortunately, very little information is available on the quality and/or clinical efficacy of medication based on C. Bovis. To ensure sustainable use of traditional therapeutic agents derived from C. Bovis, we felt that several issues needed to be addressed: 1) the source of the $C$. Bovis materials and quality control; 2) the role of taurine in the efficacy of $C$. Bovis.
\end{abstract}

Methods: Nine samples of natural C. Bovis and its substitutes were collected. ICP-MS was used for elemental analysis and the characterization was performed by principal component analysis (PCA) and soft independent modeling of class analogy (SIMCA) as multivariate approaches. The efficacy of C. Bovis was evaluated for morphology, viability and beating pattern on cultured cardiac myocytes and/or fibroblasts.

Results: PCA and multi-elemental focus was effective in discriminating C. Bovis samples derived from different habitats. A satisfactory classification using SIMCA was obtained among Australia C. Bovis, other habitats and the substitutes. Australian samples had better batch uniformity than other habitats and were composed of fewer elements. We have used Australian C. Bovis for assessment on its bioactive compounds. Rat cardiac cells incubated with C. Bovis extract $(0.01-0.1 \mathrm{mg} / \mathrm{ml})$ maintained normal morphology, viability and beating pattern. Cardiac myocytes and fibroblasts treated for $48 \mathrm{~h}$ with CA $(0.5 \mathrm{mM})$ or DCA $(0.1 \mathrm{mM})$ caused cell injury, as reflected by changes in appearance and a reduction of viability detected by the MTS assay. In cardiomyocytes, $0.5 \mathrm{~h}$ exposure of CA $(0.5 \mathrm{mM})$ markedly decreased the velocity ratio of beating, whereas the simultaneous addition of $1 \mathrm{mM}$ taurine largely prevented the decrease.

Conclusions: The multi-elemental focus provided some references for the quality control and the efficacy of C. Bovis. Taurine partly attenuated the harmful actions of bile acids. It is plausible that the relationship between taurine and the bile acids contributes to therapeutic effect of $C$. Bovis.

\section{Background}

Calculus Bovis (Goo in Japanese, Niuhuang in Chinese, the gallstone of Bos Taurus domesticus Gmmelin) is one of the most precious and commonly-used medicinal materials in Japan and China. Its use was first recorded in "Shennong Bencao Jing" (Divine Farmer's Materia Medica Classic) more than two thousand years ago, and now it has been used in 650 out of the 4500 traditional

\footnotetext{
* Correspondence: kyokot@museum.osaka-u.ac.jp

${ }^{1}$ The Museum of Osaka University, Toyonaka, Osaka, Japan

Full list of author information is available at the end of the article
}

Chinese medicines [1,2]. In the 230 cardioactive types of Japanese OTC drugs, 228 drugs contain C. Bovis, which has the effects of sedation, anti-hyperspasmia, relieving fever, diminishing inflammation and normalizing function of the gallbladder $[3,4]$. A source of supply for C. Bovis is far behind the actual need since the natural occurrence of $C$. Bovis is very rare. In China, great efforts have been taken for some substitutes of natural C. Bovis. The safety and efficacy of C. Bovis is closely correlated with quality of the source materials. Unfortunately, very little information is available on the quality 
and/or clinical efficacy of medication based on traditional animal sources.

We have previously reported on the anti-arrhythmic actions of $C$. Bovis as a traditional knowledge-product and suggested these effects are partly mediated by taurine [3]. To ensure sustainable use of traditional therapeutic agents derived from C. Bovis, we felt that several issues needed to be addressed: 1 ) the source of the C. Bovis preparation and quality control; 2) the role of taurine in the cardio-active efficacy of $C$. Bovis.

\section{Materials and methods}

\section{Samples and reagents}

Thirteen samples of natural C. Bovis and its substitutes (artificial C. Bovis, cultured C. Bovis) from various places were collected and are listed in Table 1 . Nine batches of natural C. Bovis samples produced from Australia, Argentina, Brazil, Guatemala, Mexico and Kenya were purchased from Tochimoto Tenkai-Do (Osaka, Japan). All materials used in this study were stored in the Department of Applied Pharmacognosy, the Museum of Osaka University, Japan. Cholic acid (CA), deoxycholic acid (DCA) and glycine-/taurine-conjugated bile acids were purchased from Nacalai Tesque, Inc. (Kyoto, Japan). Other regents were of analytical grade.

\section{Preparation of Calculus. Bovis-extract and taurine measurement}

Water or DMSO was used as the solvent to extract the desired components. Natural C. Bovis contains a high concentration of bile acid, which adversely affects cells by disrupting their cell membrane. Each concentration of major bile acids in C. Bovis (100\% DMSO) was equivalent to $0.5 \mathrm{mM}$ CA, $0.1 \mathrm{mM}$ DCA and $0.5 \mathrm{mM}$ taurocholic acid (:TCA), respectively [3]. To minimize the extraction of these bile acids, water or DMSO/water $(=2: 1)$ was used as the solvent to extract the desired components. Ten mg of well-pulverized crude drug was extracted with $5 \mathrm{ml}$ of water at room temperature. The extract was centrifuged at $12000 \mathrm{x} \mathrm{g}$ for $20 \mathrm{~min}$ at $4^{\circ} \mathrm{C}$. A final concentration of C.Bovis extract to the culture medium was $0.01-0.1 \mathrm{mg} / \mathrm{ml}$ according to the human OTC doses.

The taurine or bile acids content of C. Bovis derived samples was measured by the procedure using ultra performance liquid chromatography (LaChromUltra, HITACHI, Inc., Tokyo, Japan) equipped with a L-2485U fluorescence detector or L-2400U UV detector, respectively.

\section{ICP-MS measurement and multivariate analysis}

Major and trace elements in materials were measured by using inductively coupled plasma mass spectrometry (:ICP-MS) [5]. The C. bovis powder $(10 \mathrm{mg})$ was added to $1 \mathrm{ml}$ of $\mathrm{HNO}_{3}$ (Nacalai Tesque, Kyoto, Japan), vortexed and left standing overnight at room temperature. Then, $100 \mu \mathrm{l}$ of samples were diluted with $9.9 \mathrm{ml}$ of water and filtered through $0.45 \mu \mathrm{m}$ pore size hydrophilic PTFE membrane filter (Millipore, Billerica, MA). ICPMS analysis was performed on the Agilent 7500 Series ICP-MS (Agilent Technologies, Inc., Santa Clara, CA). Among the attained data, the elements which were detected as more than $1 \mu \mathrm{g} / \mathrm{l}$ in the solvent were selected. Each data in the chart was shown as relative concentration. Principal component analysis (PCA) and soft independent modeling of class analogy (SIMCA) were used as exploratory techniques and classification procedures, respectively [6]. Variables such as $\mathrm{Na}, \mathrm{Mg}$, $\mathrm{Al}, \mathrm{K}, \mathrm{Ca}, \mathrm{V}, \mathrm{Cr}, \mathrm{Mn}, \mathrm{Fe}, \mathrm{Co}, \mathrm{Ni}, \mathrm{Cu}, \mathrm{Zn}, \mathrm{Ge}, \mathrm{As}, \mathrm{Mo}$, $\mathrm{Hg}$ and $\mathrm{Pb}$ have been used as discriminating factors.

Table 1 Summary of investigated samples

\begin{tabular}{|c|c|c|c|c|c|}
\hline No. & Species & Properties & Source & Collection site & Collection date \\
\hline 1 & Natural C.bovis & Natural, PW ${ }^{1)}$ & Tochimoto co. & Australia-1 & 2006 \\
\hline 2 & Natural C.bovis & Natural, PW & Tochimoto/Toyama & Australia-2 & 2001 \\
\hline 3 & Natural C.bovis & Natural, PW & Tochimoto/Toyama & Argentine & 2001 \\
\hline 4 & Natural C.bovis & Natural, PW & Tochimoto/Toyama & Brazil & 2001 \\
\hline 5 & Natural C.bovis & Natural, PW & Tochimoto/Toyama & Guatemala & 2001 \\
\hline 6 & Natural C.bovis & Natural, PW & Tochimoto/Toyama & Mexico & 2001 \\
\hline 7 & Natural C.bovis & Natural, PW & Tochimoto/Toyama & Kenya & 2001 \\
\hline 8 & Natural C.bovis & Natural, $\mathrm{CL}^{2)}$ & Takahashi K. ${ }^{3)}$ & China & 2007 \\
\hline$\underline{9}$ & Natural C.bovis & Natural, CL & Osaka univ. ${ }^{4)}$ & India & 1978 \\
\hline 10 & Artificial C.bovis & In vitro prepared, PW & Takahashi K. & China & 2007 \\
\hline 11 & Artificial C.bovis & In vitro prepared, PW & Osaka univ. & China & 1971 \\
\hline 12 & Artificial cultured C.bovis & In vitro cultured, $\mathrm{CL}$ & Tochimoto co. & China, Hubei & 2009 \\
\hline 13 & Artificial cultured C.bovis & In vitro cultured, $\mathrm{CL}$ & Tochimoto co. & China, Anhui & 2009 \\
\hline
\end{tabular}

The abbreviations of properties: ${ }^{1)} \mathrm{PW}$ : powder, ${ }^{2)} \mathrm{CL}$ : clod. ${ }^{3)}$ Samples were purchased from local stores in Shenyang by Takahashi $\mathrm{K} .{ }^{4)}$ Historical specimens stored in the museum of Osaka University. 


\section{Cell culture and assessment on bioactive compounds of Calculus Bovis}

Primary cultures of cardiac cells from 1-day-old Wister rats were prepared according to the methods described previously [7]. All experimental procedures were approved by the Animal Care Committee of Osaka University and conformed to international guidelines.

Cardiac cells were seeded in a 96-well plate and were determined by MTS assay using CellTiter $96^{\circ}$ aqueous one solution reagent (Promega Corporation) [8]. After $48 \mathrm{~h}$ incubation in serum-containing culture medium, medium was transferred to serum-free medium. After 24 h incubation, cells were treated with C. Bovis, bile acids and taurine for $48 \mathrm{~h}$. Following removal of the C. Bovis, cells were washed with phosphate-buffered saline (PBS) twice. The cells were then incubated in serum free maintenance medium $(100 \mu \mathrm{l})$ with one solution reagent $(20 \mu \mathrm{l})$ for $3 \mathrm{~h}$. Cell viability was defined as the ratio (expressed as a percentage) of absorbance of treated cells to untreated cells at $490 \mathrm{~nm}$.

The beating status of cultured myocardial cells was monitored with an inverted phase-contrast microscope and was measured by using a photosenser equipped with a microcomputer (P-200, Adachi Co.,Osaka). The shape and location of each cell in the dish were recorded before initiating the experiments [9]. The beating properties of the same cells were monitored following the chosen perturbation.

\section{Statistic analysis}

Statistical significance was determined by the Student's t-test. Each value was expressed as the mean \pm S.E. Differences were considered statistically significant when the calculated $\mathrm{P}$ value was less than 0.05 .

\section{Results}

\section{Quality characterization of Calculus Bovis using pattern} recognition techniques and multiple element data

It is an important issue to comprehensively evaluate the different species of $C$. Bovis, so as to ensure the clinical efficacy of this medicinal material. The provisions of Chinese Pharmacopeia [4] for some substitutes of natural C. Bovis were summarized in Table 2. One has been so-called artificial $C$. Bovis, being a mixture of bile salts, bilirubin, taurine and some other ingredients that have been found and believed to have contributed to the therapeutic effects of natural C. Bovis. Another is the socalled cultured C. Bovis, which is either the induced gallstones in animals in vivo, or those produced in vitro under the conditions mimicking the gallstone formation process in vivo [2].

On the other hand, reference values for C. Bovis in Japanese Pharmacopeia [10] is as follows: spherical or massive stone, $1-4 \mathrm{~cm}$ in diameter; externally yellow-
Table 2 Charcteristics of Calculus Bovis in Chinese Pharmacopoeia 2005

\begin{tabular}{lll}
\hline Crude drugs & Ingredients & Compounds \\
\hline $\begin{array}{l}\text { Natural Calculus } \\
\text { Bovis, }\end{array}$ & Bos taurus domesticus Gmelin & CA : $\geq 4.0 \%$ \\
Niuhuang & & Bilirubin $\geq 35.0 \%$ \\
& & Total ash $\leq$ \\
CALCULUS BOVIS & & $10.0 \%$ \\
\hline Artificial Calculus & Ox bile-powder (CA: $\geq 42.0 \%)$ & \\
Bovis & Cholic acid:CA ( $\geq 80.0 \%)$ & \\
Rengong Niuhuang & Hyodeoxycholic acid:HCA & CA : $\geq 13.0 \%$ \\
& Taurine & Bilirubin : $\geq$ \\
CALCULUS BOVIS & Bilirubin ( $\geq 90 \%)$ & $0.63 \%$ \\
ARTIFACTUS & Cholesterol, Trace elements & \\
& & \\
\hline In-vitro cultured & Fresh bile of Bos taurus & \\
Calculus Bovis & domesticus Gmelin & \\
Tiwai Peiyu & & CA : $\geq 6.0 \%$ \\
Niuhuang & Cholic acid:CA ( $\geq 95.0 \%)$ & Bilirubin : $\geq$ \\
CALCULUS BOVIS & Ca Bilirubinacet complexes & $35.0 \%$ \\
SATIVUS & (CA $\geq 43.0 \%)$ & \\
& Deoxycholic acid:DCA ( $\geq 95.0$ & \\
\hline
\end{tabular}

China Pharmacopoeia Committee: Pharmacopoeia of the People's Republic of

China, $1^{\text {st }}$ Div (2005 edition) Beijing, China Chemical Industry Press 2005

brown to red-brown; light, fragile and easily broken. Fractured surface shows yellow-brown to red-brown annular rings, often containing white granular substances or thin layers in these annular rings. Odor, slight; taste, slightly bitter, followed by slight sweetness. Namely, the form, colour, smell and very importantly the taste are some of the sensory indicators, on the basis of traditional knowledge, to test for quality.

Therefore, mulitiple elements in C. Bovis materials of natural and substitutes were determined by using ICPMS. Eighteen element patterns for each sample of C. Bovis were illustrated in Figure 1. High differences can be observed in the elemental composition among the samples, especially for some elements such as $\mathrm{Zn}$ and $\mathrm{Al}$. Na and $\mathrm{Mn}$ are similar components in the samples of natural C. Bovis. Australian samples were composed of fewer elements without toxic metals such as As and $\mathrm{Hg}$.

In total, 18 elements were determined in a range of 13 samples (9 natural C. Bovis, 4 artificial substitutes). The result indicated the variation among $C$. Bovis samples under different developmental conditions (Figure 2). PCA can classify 13 samples as shown in Figure 2-A. Thirteen samples were separated by their origin, Australian materials, other countries and substitutes. Australian materials were classified in the group of samples from other countries. The elements, $\mathrm{Mn}, \mathrm{Zn}$ and $\mathrm{Al}$, were found by PCA to contribute the classification of 13samples. A satisfactory classification using SIMCA was obtained both for Australia C. Bovis and the substitutes, namely $100 \%$ of cases correctly classified (Figure 2-B). 


\section{Australia (1)}

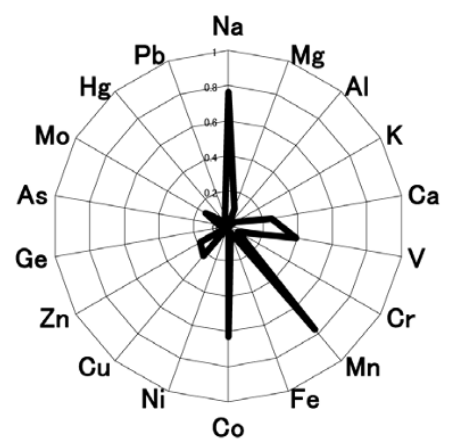

Kenya (7)

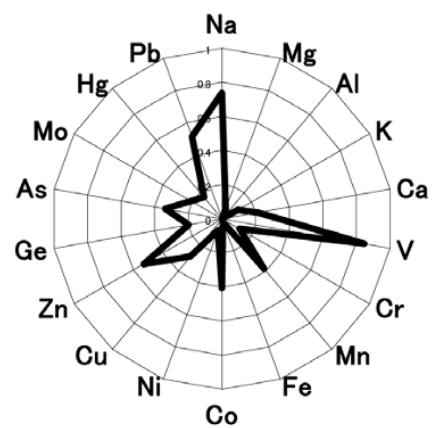

China (8)

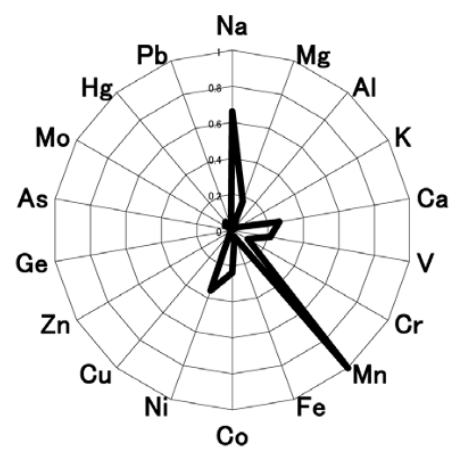

India (9)

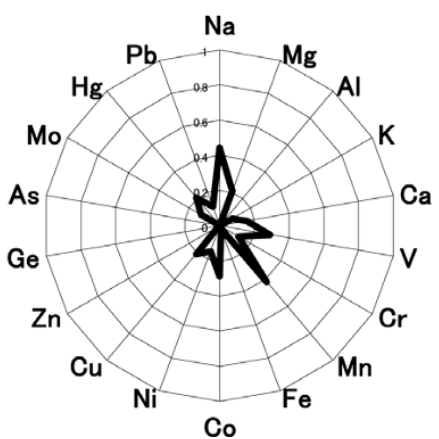

Brazil (4)

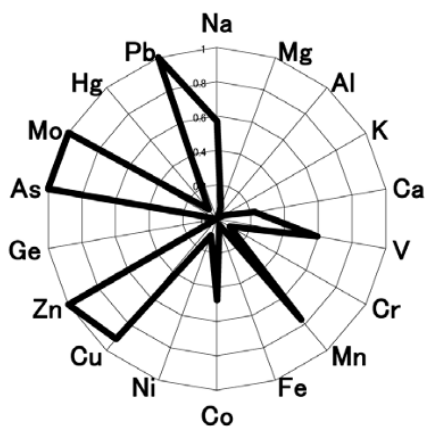

Guatemala (5)

Figure 1 Multiple element patterns of natural Calculus Bovis samples derived from different habitats. The number in parentheses matched to the number of samples in Table 1. The elements which were detected more than $1 \mathrm{ng} / \mathrm{l}$ in the solvent were selected. Each data in the chart was shown as relative concentration. Relative concentration was calculated by setting the maximum concentration of each element contained in samples as $1(n=3)$.

The role of taurine on the cardioactive efficacy of Calucus Bovis

In this study, we have used natural C. Bovis originated from Australia for ensuring its efficacy. The major constituents of this extract were bile acids (cholic acid: CA, deoxycholic acid: DCA, taurocholic acid:TCA) and taurine. The average bile acid concentration in Australian C. Bovis extract $(0.1 \mathrm{mg} / \mathrm{ml})$ was equivalent to $0.32 \mathrm{mM}$ CA, $0.32 \mathrm{mM}$ DCA and $0.24 \mathrm{mM}$ TCA, respectively (not data shown).

To assess whether C.Bovis extract had cytotoxic effects on cardiac cells, morphological injury and cell viability using MTS assay were measured. Figure 3-A showed the influence of different doses of C.Bovis extract on the morphology of cultured cardiomyocytes. Addition of $C$. Bovis extract to the culture medium to give a final concentration of $0.01-0.1 \mathrm{mg} / \mathrm{ml}$ had no change during $24 \mathrm{~h}$ (Figure 3-A). At the dose of $0.1 \mathrm{mg} / \mathrm{ml}$, treatment with C.Bovis extract for $48 \mathrm{~h}$ barely influenced the growth of cardiac myocytes and fibroblasts despite the bile acid contents of $0.2 \sim 0.3 \mathrm{mM}$ (Figure 4 ). The presence of $1 \mathrm{mM}$ DCA showed pronounced injury, including ballooning and cell lysis on cardiac myocytes and fibroblasts after $1 \mathrm{~h}$ (Figure 3-B).

Cardiac myocytes and fibroblasts treated for $48 \mathrm{~h}$ with CA or DCA caused cell injury, as reflected by changes in appearance and a reduction of viability detected by the MTS assay (Figure 4). The cell viability of both cells was reduced by approximately $70 \%$ when the cells were treated with $0.1 \mathrm{mM}$ DCA, whereas TCA at a concentration of $0.5 \mathrm{mM}$ had no effect over a 48 -h period. Treatment with $0.5 \mathrm{mM}$ CA caused a decrease in viability of fibroblasts by $66 \%$ of control after $48 \mathrm{~h}$. Cardiomyocyte was not significantly altered its viability by treatment with $0.5 \mathrm{mM} \mathrm{CA}$ for $48 \mathrm{~h}$.

Figure 5 shows a typical photograph and the beating status recorded by a photosensor equipped with microcomputer on cardiomyocytes. Changes in morphology and beating status were estimated for each cell on 12 points and expressed as percent of the total points of 


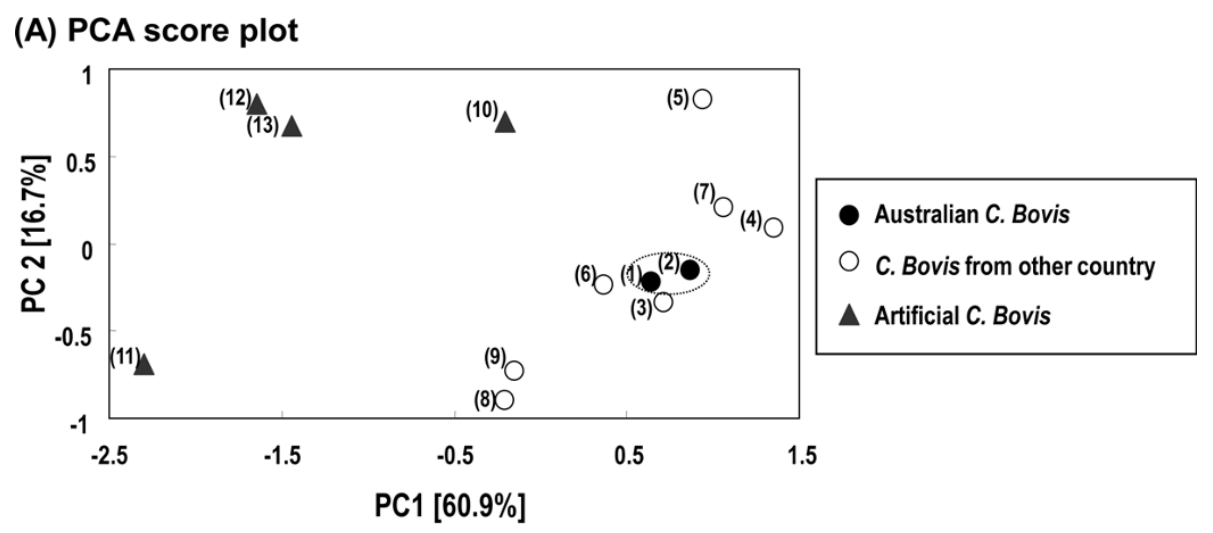

(B) SIMCA (Soft Independent Modeling of Class Analogy)

\begin{tabular}{|c|c|c|c|c|}
\hline & Pred Australia & Pred Other countries & Pred Others & No match \\
\hline Australia & $\mathbf{2}$ & $\mathbf{0}$ & $\mathbf{0}$ & $\mathbf{0}$ \\
\hline Other countries & $\mathbf{0}$ & $\mathbf{7}$ & $\mathbf{0}$ & $\mathbf{0}$ \\
\hline Artificial others & $\mathbf{0}$ & $\mathbf{0}$ & $\mathbf{4}$ & $\mathbf{0}$ \\
\hline
\end{tabular}

Figure 2 Quality characterization of Calculus Bovis using pattern recognition techniques and multiple element data. (A) PCA score plot according to multiple element data. The number in parentheses matched to the number of samples in Table 1. Variables such as $\mathrm{Na}$, Mg, Al, $\mathrm{K}$, $\mathrm{Ca}, \mathrm{V}, \mathrm{Cr}, \mathrm{Mn}, \mathrm{Fe}, \mathrm{Co}, \mathrm{Ni}, \mathrm{Cu}, \mathrm{Zn}, \mathrm{Ge}, \mathrm{As}, \mathrm{Mo}, \mathrm{Hg}$ and Pb have been used as discriminating factors. Percentages in square brackets were contribution values. (B) Multivariate characterization by SIMCA. Symbols: Australian C. Bovis; $(\bullet)$; other countries (०); artificial samples ( $\bullet$ ). Each point represented the mean values. $(n=3)$.

cells observed (not data sown). As shown Figure 5-B-d, untreated cells showed the rhythmic beating detected by vertical displacements. There is no significant inhibition on the beating status when $0.1 \mathrm{mg} / \mathrm{ml}$ of C.Bovis extract is administered (Figure 5-B-f). All cells in observed 12 points with/without C.Bovis kept to beat synchronously over a $3 \mathrm{~h}$ period without morphological changes. However, CA at a concentration of $0.5 \mathrm{mM}$ caused a $50 \%$ beat cessation of cardiomyocytes (Figure 5-B-e).

In China Pharmacopoeia, bile acids are the major active components and CA has been used as the chemical marker for quality control of C. Bovis and its substitutes [4]. Taurine is also provided as an ingredient of artificial C. Bovis. In the present study, taurine content in several samples of natural C. Bovis and its substitutes varied widely between $0.035 \sim 104.7 \mathrm{mg} / \mathrm{g}$. The mean taurine concentration for Australian natural C. Bovis in the study was $0.32 \pm 0.19 \mathrm{mg} / \mathrm{g}$ C.Bovis $(2.56 \mu \mathrm{mol} / \mathrm{g})$. The values for the highest and lowest taurine concentrations were $3.92 \mathrm{mg} / \mathrm{g}$ of Chinese and $0.035 \mathrm{mg} / \mathrm{g}$ of Mexican one, respectively.

We have previously reported on the anti-arrhythmic actions of C. Bovis and suggested these effects are partly mediated by $0.1 \mathrm{mM}$-taurine [3]. Therefore, we tested the effects of taurine on CA-induced beating abnormality. In cardiomyocytes, $0.5 \mathrm{~h}$ exposure of CA markedly decreased the velocity ratio of beating from $69 \%$ to $18 \%$, whereas the simultaneous addition of $1 \mathrm{mM}$ taurine largely prevented the decrease, restoring the beating ratio to $47 \%$ (Figure 6).

\section{Discussion}

Natural C. bovis is obtained as a valuable by-product from animals used for meat production. As the natural occurrence is very rare, great efforts have been taken for some substitutes of natural C. Bovis. In 2004, it was reported that $98 \%$ of $C$. Bovis used in China was artificial [2]. However, due to the different developmental conditions, chemical constituents of substitutes might be different from those natural C. Bovis, which thus may lead to the variation of therapeutic effects. In Japan, all materials of $C$. Bovis are imported from several countries such as Australia, Latin America, Africa, India and China [11]. Empirically, Japanese importers evaluated Australian C. Bovis as a high quality product without scientific reasons. The disordered use and abuse result in the loss of original pharmaceutical actions and therapeutic values of this natural product. Therefore, to ensure the quality of $C$. Bovis and its substitutes, an efficient quality control approach is urgently needed. Correctly characterizing the traditional animal materials is the inevitable starting point for studying C. Bovis.

First, we have characterized Natural C. Bovis originating from Australia using pattern recognition techniques and major and trace elements data (Figure 1,2). PCA and multi-elemental focus was effective in discriminating 


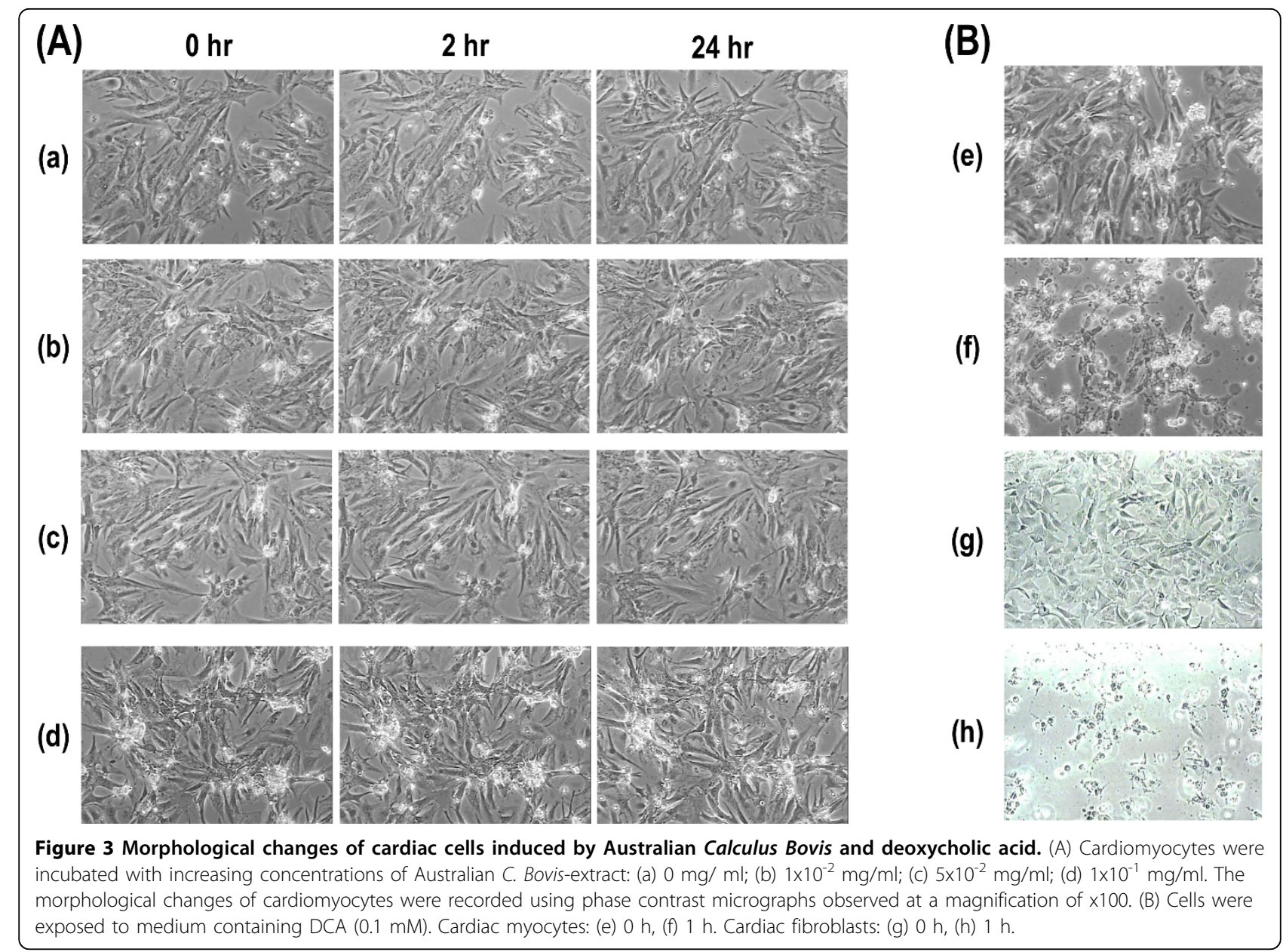

(A)

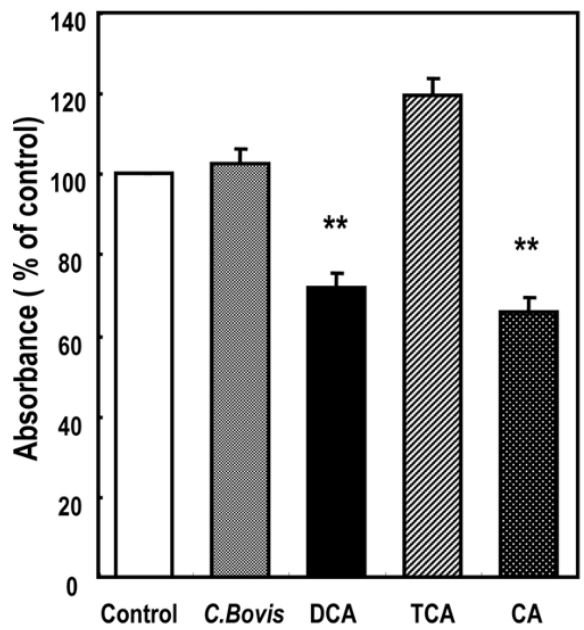

(B)

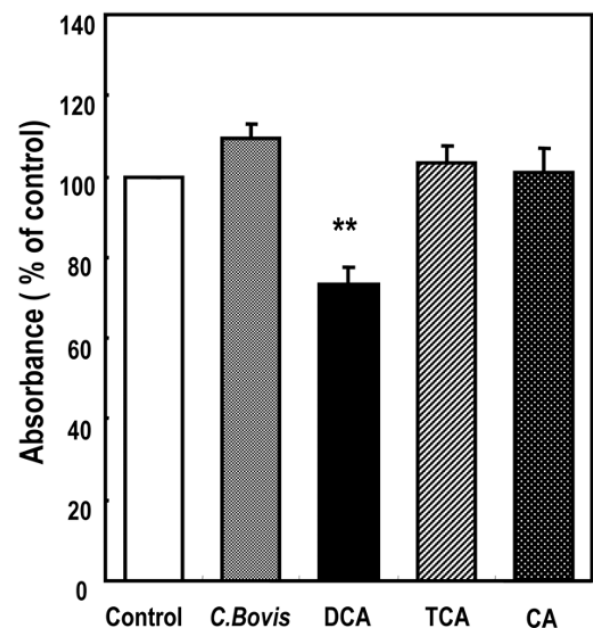

Figure 4 Influences of Calculus bovis -related substances on viability of cardiac cells. Cells were incubated with C. Bovis-ext. and three bile acids for $48 \mathrm{~h}$. Values were expressed as percent of control, in which the control cells were untreated. Data expressed means \pm SEM obtained from of 12-14 samples from triplicate experiments. Cardiac fibroblasts (A) and myocytes (B) were treated with C. Bovis (1x10 $\left.{ }^{-1} \mathrm{mg} / \mathrm{ml}\right)$, DCA (0.1 $\mathrm{mM}), \mathrm{TCA}(0.5 \mathrm{mM})$ and $\mathrm{CA}(0.5 \mathrm{mM})$, respectively. ${ }^{* *} \mathrm{P}<0.01$ compared with C. Bovis-ext. 


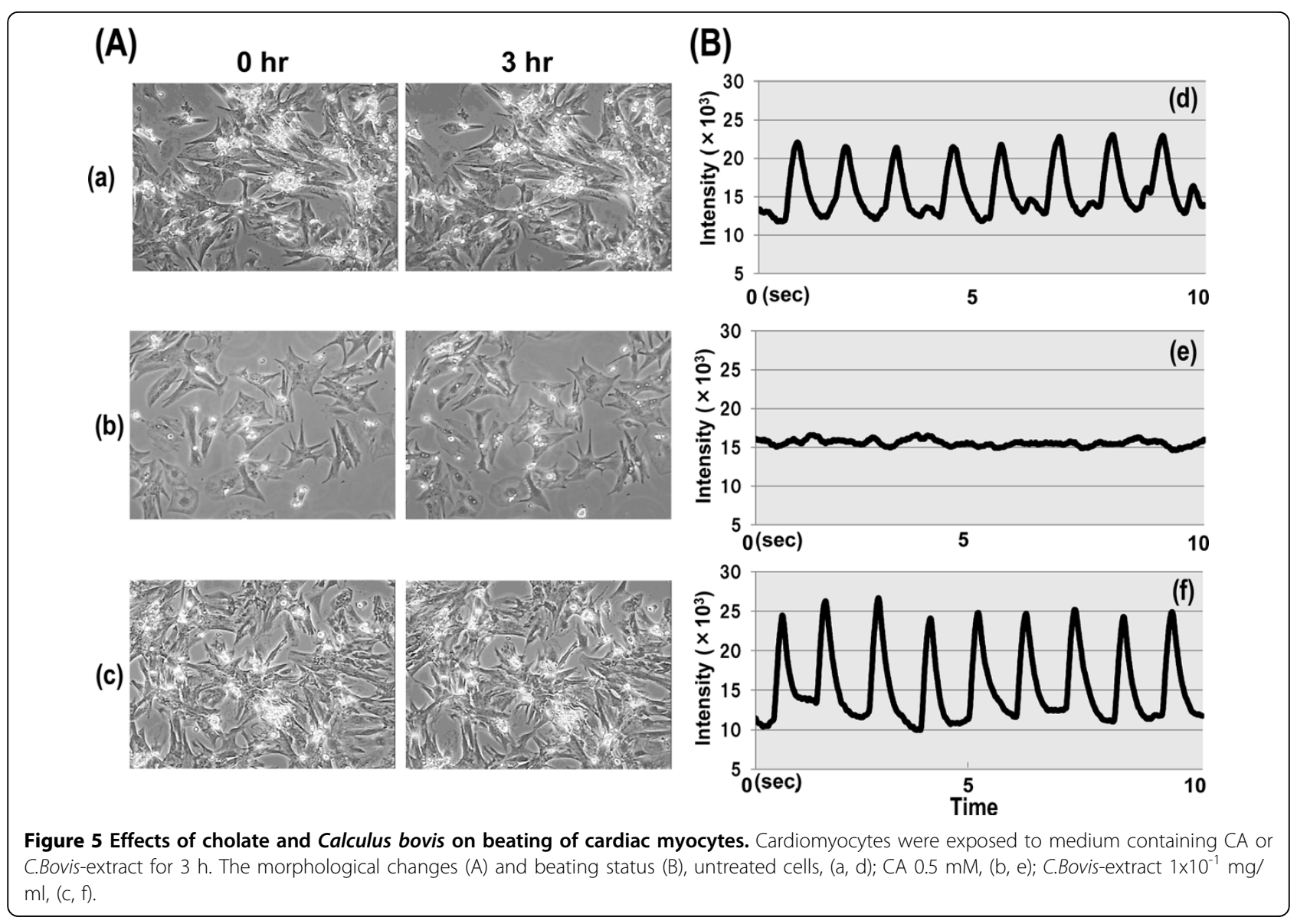

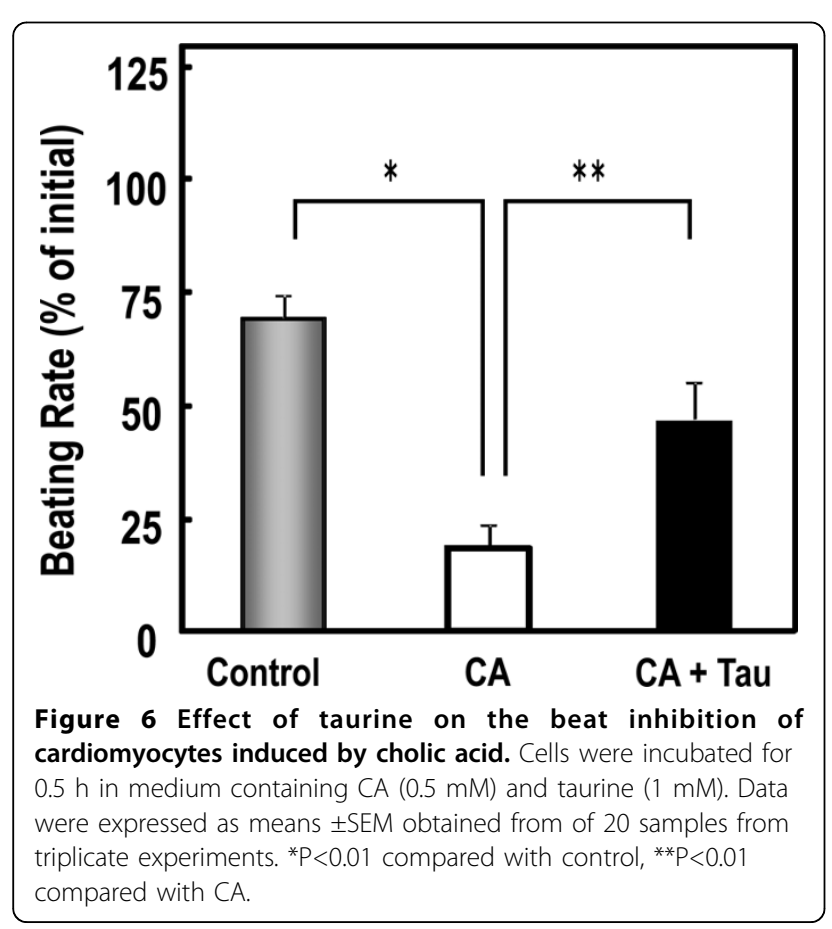

C. Bovis samples derived from different habitats. There is general agreement among the experts/importers on crude drugs that Australian C. Bovis is quite a good quality on the basis of traditional knowledge. Interestingly, natural grouping of Australian samples was observed (Figure 2). Namely, the Australian ones had better batch uniformity than other habitats and were composed of fewer elements. The result indicated the variation among C. Bovis samples under different developmental conditions such as natural or artificial.

Secondly, we have used Australian C. Bovis for assessment on its bioactive compounds. Chemical and pharmacological investigations on C. Bovis resulted in discovering several kinds of bioactive components, i.e. bile acids, bilirubin and some inorgamic salts $[1,12,13]$. CA has been used as the chemical marker for quality control of $C$. Bovis in the provisions of Chinese Pharmacopeia (Table 2) [4]. Taurine and CA are also one of the ingredients for artificial substitutes (Table 2) [4]. Since the content of CA,DCA and taurine in C. Bovis extract derived from different sources can vary enormously, its effect on cardiomyocytes needs to be analyzed after normalization based the value of taurine or CA/DCA. This is particularly important because CA/ DCA and taurine have opposite effect on cardiomyocytes. 
In the present study, cardiac cells treated with CA or DCA caused cell injury, as reflected by the morphological change and a reduction of cell viability (Figure 3,4 ). Rat cardiac cells incubated with C. Bovis extract (0.01$0.1 \mathrm{mg} / \mathrm{ml}$ ) maintained a normal morphology, viability and beating pattern (Figure 3, 4, 5). However, cardiac cells treated with CA or DCA caused cell injury, as reflected by the morphological change and a reduction of cell viability. TCA, a major constituent in C. Bovis, also caused loss of synchronous beating, bradycardia and cessation of contraction in cultured rat cardiomyocytes $[14,15]$. We demonstrated a reduced rate of contraction and proportion of beating cells when rat cardiomyocytes were exposed to CA. $0.5 \mathrm{~h}$ exposure of CA markedly decreased the velocity ratio of beating, whereas the simultaneous addition of $1 \mathrm{mM}$ taurine significantly prevented the decrease (Figure 6). Our previous data reported that $C$. Bovis extract was effective in protecting against the abnormal beating induced high $\mathrm{Ca}^{2+}$, and its efficacy was interfered by an inhibitor of taurine transport, bata-alanine $[3,16]$. It has been recognized that taurine may have some beneficial effects due to, for instance, its antioxidant or anti-apoptotic capacity [17-20]. It is plausible that the relationship between taurine and the bile acids contribute to the therapeutic effect of C. Bovis.

Finally, this work provided some references for the quality control of $C$. Bovis materials. For practical purposes and for conservation reasons [21], it is desirable to find acceptable substitutes to C. Bovis used in traditional medicines. And it is necessary to make use of modern scientific tools to establish verifiable synthetic substitutes as sustainable replacements for medicinal resources. Future work would be focused on the different pharmacological actions of these natural C. Bovis and the substitutes of some spurious breeds.

\section{Conclusions}

The present work provided some references for the quality control and the efficacy of C. Bovis. PCA and multi-elemental focus was effective in discriminating C. Bovis samples derive from different habitats. Taurine partly attenuated the harmful actions of bile acids. It is plausible that the relationship between taurine and the bile acids contribute to the therapeutic effect of $C$. Bovis.

\footnotetext{
Abbreviations

C.Bovis: Calculus Bovis; ICP-MS: inductively coupled plasma mass spectrometry; PCA: principal component analysis; SIMCA: soft independent modeling of class analogy; CA: cholic acid; DCA: deoxycholic acid; TCA: taurocholic acid; GCA: glycocholic acid; TDCA: taurodeoxycholic acid.
}

\section{Acknowledgements}

This article has been published as part of Journal of Biomedical Science Volume 17 Supplement 1, 2010: Proceedings of the 17th International
Meeting of Taurine. The full contents of the supplement are available online at http://www.jbiomedsci.com/supplements/17/S1.

We thank Dr. Feng Qiu and Dr. Xiao-Long Hou for the support of the materials, and Dr. Takeshi Bamba for help with UPLC and multivariate analysis.

\section{Author details}

${ }^{1}$ The Museum of Osaka University, Toyonaka, Osaka, Japan. ${ }^{2}$ Graduate School of Pharmaceutical Sciences, Osaka University, Suita, Osaka, Japan.

${ }^{3}$ Radioisotope Research Center, Osaka University, Suita, Osaka, Japan.

${ }^{4}$ Nagahama Institute of Bio-Science and Technology, Nagakama, Shiga, Japan. ${ }^{5}$ School of Medicine, University of South Alabama, Mobile, AL, USA.

\section{Authors' contributions}

K.T. and Y.A. conceived the experiments. K.T. and Y.A. performed the experiments with K.S. and analysed the data together with M.K. and T. S. S. W.S helped to edit the manuscript.

\section{Competing interests}

This work was supported in part by OTC Self-Medication Promotion Foundation 2009 and a grant from Tochimoto Tenkaido Co. (Osaka Japan).

Published: 24 August 2010

\section{References}

1. Yang MZ, Chi C, Chi P: Development of 43 years (1949-1992) of studies on Calculus Bovis in China. Chi J Ethnomed Ethnopharm (Chin) 1996, 18:27-35.

2. Qin X: Bilirubin would be the indispensable component for some of the most important therapeutic effects of Calculus Bovis (Niuhuang). Chin Med J 2008, 121:480.

3. Takahashi K, Azuma Y, Kobayashi S, Azuma J, Takahashi Ko, Schafer SW, Hattori $M$, Namba T: Tool from traditional medicines is useful for healthmedication: Bezoar Bovis and taurine. Adv Exp Med Biol. 2009, 643:95-103.

4. China Pharmacopoeia Committee: Pharmacopoeia of the People's Republic of China. 1st Div (2005 edition) Beijing, China Chemical Industry Press 2005.

5. Romaris-Hortas V, Garcia-Sartal C, Barciela-Alonso MC, Moreda-Pineiro A, Bermejo-Barrera P: Characterization of edible seaweed harvested on the Galician Coast (northwestern Spain) using pattern recognition techniques and major and trace element data. J Agric Food Chem. 2010, 58:1986-1992.

6. Ariyama $\mathrm{K}$, Horita $\mathrm{H}$, Yasui $\mathrm{A}$ : Chemometric techniques on inorganic elements composition for the determination of the geographic origin of Welsh onions. Anal Sci 2004, 20:871-877.

7. Takahashi K, Ouyang X, Komatsu K, Nakamura N, Hattori M, Baba A, Azuma J: Sodium tanshinone IIA sulfonate derived from Danshen (Salvia milriorrhiza) attenuates hypertrophy induced by angiotensin II in cultured neonatal rat cardiac cells. Biochem Pharmacol 2002, 64:745-749.

8. Hou XL, Takahashi K, Kinoshita N, Qiu F, Tanaka K, Komatsu K, Takahashi Ko, Azuma J: Possible inhibitory mechanism of Curcuma drugs on CYP3A4 in 1 alpha, 25 dihydroxyvitamin D3 treated Caco-2 cells. Int J Pharm 2007, 337:169-177.

9. Ouyang X, Takahashi K, Komatsu K, Nakamura N, Hattori M, Baba A, Azuma J: Protective effects of Salvia milriorrhiza on angiotensin IIinduced hpertrophic responses in neonatal rat cardiac cells. Jpn J Pharmacol 2001, 87:289-296.

10. [http://jpdb.nihs.go.jp/jp15e].

11. Namba T: Goo (Bezoar Bovis). Coloured Illustrations of WAKANYAKU Osaka Hoikusha Publishing Co.LtdNamba T 1980, 2:269-272.

12. Zhang $\mathrm{HZ}$ : Functions of covalently and ionically bonded bilirubin in Calculus Bovis. Chi J Biochem Pharm (Chin) 2003, 24:199.

13. Yan SK, Wu YW, Liu RH, Zhang WD: Comparative study on major bioactive components in natural, artificial and in-vitro cultured Calculus Bovis. Chem Pharm Bull 2007, 55:128-132.

14. Gorelik J, Harding S, Shevchuk Al, Koralage D, Lab M, Swiet M, Korchev Y, Williamson C: Taurocholate induced changes in rat cardiomycyte contraction and calcium dynamics. Clinical Science 2002, 103:191-200.

15. Gorelik J, Shevchuk A, Swiet M, Lab M, Korchev Y, Williamson C: Comparison of the arrhythmogenic effects of tauro- and 
glycoconjugates of cholic acid in an in vitro study of rat cardiomyocytes. BJOG 2004, 111:867-870.

16. Takahashi K, Azuma J, Park S, Awata N, Kishimoto S, Namba T, Schaffer SW: Pharmacological study of a traditional Chinese medicine:effect of Bezor Bovis on the irregular beating pattern of cultured mouse myocardial cells. Res Commun Chem Pathol Pharmacol 1989, 63:317-330.

17. Takatani T, Takahashi K, Uozumi Y, Matsuda T, Ito T, Fujio Y, Azuma J: Taurine prevents the ischemia-induced apoptosis in cultured neonatal rat cardiomyocytes through Akt/caspase-9 pathway. Biochem Biophys Res Commun 2004, 316:484-489.

18. Xu YJ, Arneja AS, Tappia PS, Dhalla NS: The potential health benefits of taurine in cardiovascular disease. Exp Clin Cardiol. 2008, 13:57-65.

19. Wojcik OP, Koenig KL, Zeleniuch-Jacquotte A, Costa M, Chen Y: The potential protective effects of taurine on coronary heart disease. Atherosclerosis 2010, 208:19-25.

20. Takahashi K, Takatani T, Uozumi Y, Ito T, Matsuda T, Fujio Y, Schaffer SW, Azuma J: Molecular mechanisms of cardioprotection by taurine on ischemia-induced apoptosis in cultured cardiomyocytes. Adv Exp Med Biol. 2006, 583:257-263.

21. Costa-Neto EM: Animal-based medicines: biological prospection and the sustainable of zootherapeutic resources. An Acad Bras Cienc 2005, 77:33-43.

doi:10.1186/1423-0127-17-S1-S44

Cite this article as: Takahashi et al:: Quality and safety issues related to traditional animal medicine: role of taurine. Journal of Biomedical Science 2010 17(Suppl 1):S44.

\section{Submit your next manuscript to BioMed Central and take full advantage of:}

- Convenient online submission

- Thorough peer review

- No space constraints or color figure charges

- Immediate publication on acceptance

- Inclusion in PubMed, CAS, Scopus and Google Scholar

- Research which is freely available for redistribution

Submit your manuscript at www.biomedcentral.com/submit 